\title{
Development of Footwork Exercise Tool Based on Android for Badminton
}

\author{
E Sepdanius $^{1 *}$, N Novselia $^{1}$, Syafrizar $^{1}$ \\ ${ }^{1}$ Faculty of Sports Science, Universitas Negeri Padang, Indonesia \\ "Corresponding author.Email: endangsepdanius@fik.unp.ac.id
}

\begin{abstract}
The research purpose was to test the acceptance and the effectiveness of footwork exercise tool based on android that was developed in badminton. The kind of this research was Research and Development. The steps of this research were (1) potential problems, (2) collecting information/data, (3) product design, (4) design validation, (5) design improvement, (6) product trial. Experts' validations were done by badminton academics and coach. The subjects of this research were beginner athletes and teenagers that have covered the basic footwork. Product acceptance test was conducted to 16 subjects. Tool effectiveness test was tested to 52 subjects. The instruments in collecting data were tool acceptance questioner and the score that was gotten by using the tool. Exercise tool was arranged automatically with 3 seconds lamp change interval in 1 minute. This tool used real time clock component with 0.001 tolerance level. Technique of analyzing data in this research was descriptive analysis technique. results showed that the experts stated the tool was appropriate to the need in improving footwork ability in badminton. 91.4\% athletes stated that footwork exercise tool based on android was received by athletes to practice. The effectiveness of tool was seen from the average score in using the tool 4.79 with the higher score 9 and the lowest 1 in 60 seconds and consistency the number of lamps that live randomly were 19 times per minute. Footwork exercise tool that is developed can be used to improve the physical condition ability that contributes in good footwork implementation.
\end{abstract}

Keywords: Footwork exercise, android, badminton

\section{INTRODUCTION}

In badminton, footwork control is one of the important parts. It becomes the important part because the controlling footstep will affect the variation of the quality of hits produced: (1). The purpose of good footwork is to make the players move efficiently to all directions. To be able to move quickly without loss of coordination required good physical condition. The physical conditions that are needed such as speed, agility, and coordination. Based on the kind of movement in footwork, it can be identified the system energy that is used. Those are alactic system energy and lactic acid endurance, starting power, reactive power, maximum strength, and power endurance; (2). Specifically the division of system energy that is used in badminton, $50 \%$ alactic, $30 \%$ lactic acid and $20 \%$ aerobic that is supplied from creatin phosphate and glycogen; (3). Agility is the important subject that is owned by badminton players; (4). The ability to move and change the direction quickly need body coordination in anticipating the ball from the oppponents 5)6). Coordination between organs of the body of one to the other is required to anticipate this activity. Therefore, there is a need of exercise that can combine two components of physical condition together. Technology is needed to help the process of getting achievement through exercise7)8).

\section{METHOD}

Development research of footwork exercise tool used research and development9) that was simplified into 6 steps, those were: 1) potential problem, 2) collecting information/data, (3) product design, (4) expert validation, (5) small scale product testing, (6) large scale product testing. Potential problem was gotten from the information collected through observation and interview with coach in the field. The results were discussed in focus group discussion to determine the problem solution. The solution that was determined through FGD was development of footwork exercise tool based on android. Next step was the development of prototype exercise tools that can be used automatically and manual through smart phone (android). The prototype was validated by three experts that were 2 experts from badminton academics and 1 coach. Small scale testing was done to test the acceptance tool for athlete. The result from small scale was used to tool revision. Large scale testing was used to test the efficiency of tool work by looking the results of participant footwork ability by using development 
tool. 68 participants followed tool testing activity. Participants consisted of badminton athlete group under 17 (U17) that have the basic footwork movement.

Table 1. Participant in research testing

\begin{tabular}{ccccc}
\hline Testing & $\mathrm{F}$ & Subject & \multicolumn{2}{c}{ Gender } \\
\cline { 3 - 5 } & & Man & Women \\
\hline $\begin{array}{c}\text { Small scale } \\
\text { testing }\end{array}$ & 16 & $\begin{array}{c}\text { Athlete } \\
\text { U17 }\end{array}$ & 10 & 6 \\
$\begin{array}{c}\text { Large scale } \\
\text { testing }\end{array}$ & 52 & $\begin{array}{c}\text { Athlete } \\
\text { U17 }\end{array}$ & 30 & 22 \\
\hline
\end{tabular}

\section{Procedure}

Before testing, participants were given the direction of using and the implementation of the tool. The tool was arranged automatically with 3 seconds lamp change interval in 1 minute with 0.001 tolerance level (This tool used Real Time Clock component or RTC). The tool's setting was done through smartphone (android) by using supporting application that was developed. The participant stood in the middle of the court. Monitor exactly was put in front, parallel with a net and faced the participant. Monitor was designed like a half of badminton court. There were 9 lamps in command panel consist of 3 lamps were in front of the court side, 3 lamps were in the middle, and 3 lamps were at the back part. There were 8 buttons on the court. Button 1 was at front left side, button 2 was at front middle, button 3 was at front right, button 4 was at middle right side, button 5 was at middle left side, button 6 was at back left side, button 7 was at back middle, and button 8 was at back right side. Monitor was connected to all buttons on the court. Participant started after three times "bib" sounds. Participant moved and pressed the button according to the lamps that lived in the monitor. The centre lamp instructed the participant to start or back to the centre of the court. When button 1 until 8 lived, the participant pressed the button before the centre button lived. Every button that was pressed before the centre button lived was a point for participant. Accumulation of points that were obtained by participant displayed on the panel command screen as the value of footwork ability.

The data obtained in acceptance and tool efficiency testing was processed by using descriptive analysis technique. The data were mean, minimum score, maximum score, total value, and frequency of interval class.

\section{RESULT AND DISCUSSION}

\section{Need Analysis}

Footwork ability was supported by physical ability such as agility, speed, and coordination. In training this physical ability needed specific exercise. Some exercise method have been discussed by 5 coaches and 3 scientists. The result of the FGD was found a kind of exercise that was suitable to develop footwork ability manually. That exercise method used plugs that put in 6 parts. The weaknesses of this method were 1) exercise intensity was hard to be determined. 2) the accuracy the use of time was inaccurate, 3) movement pace setting was inconsistent, and 4) it was hard to do randomly.

\section{Design}

From four weaknesses of this exercise, it was done a development of exercise tool by using technology that consisted of software and hardware. Tool that was developed enabled to be controlled in long distance. Hardware consisted of several command panels, application in android, and lamp on the court. Then, software was android application setting that was used as starting program and as tool work monitor.

\section{Prototype}

Using technology in exercise was an important part in developing sports' tool. Smartphone application facilitated the operator to set the implementation time. Application was connected to monitor that used bluetooth. The use of sensitive button in 8 sides of a half badminton court was to get the better result. All buttons were connected in parallel to monitor. The result was shown in monitor. The illustration of this footwork exercise tool can be seen in picture 1 . 


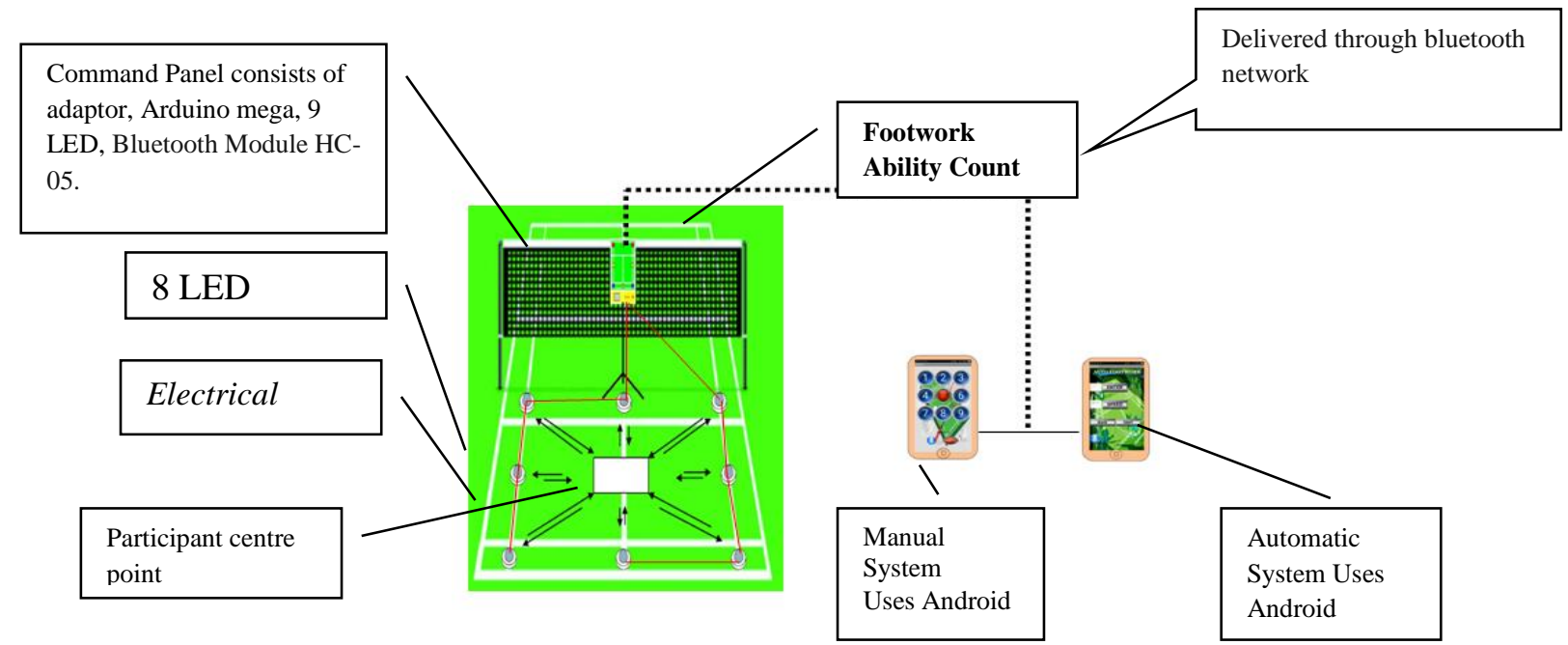

Figure 1. Prototype of footwork exercise tool in badminton

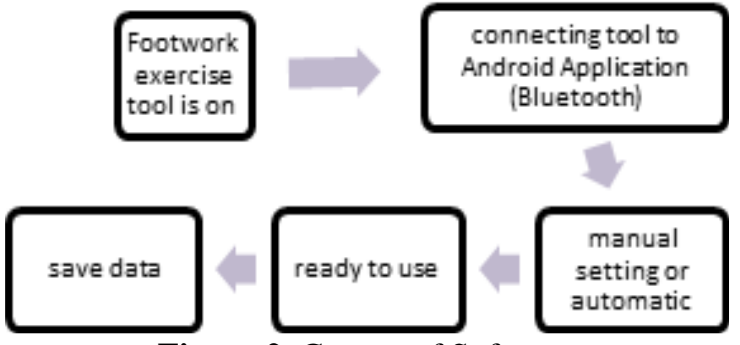

Figure 2. Groove of Software

\section{Acceptance testing and Revision}

Acceptance testing was used to see thlete's response towards the appropriateness and quality of tool. After testing, participants were given closed questioner to evaluate the product. The results were minimum score 30, maximum score 40, mean 36.56, deviation standard 3.71 , total value $\sum=585$. Frequency distribution can be seen in table 2

Table 2. Frequency Distribution of Appropriateness Testing

\begin{tabular}{|c|c|c|c|c|c|c|c|c|c|c|}
\hline No & Criteria & Formula & \multicolumn{5}{|c|}{ Assessment Criteria } & $\mathrm{F}$ & F. Relative & Percentage \\
\hline 1 & Very appropriate & $\mathrm{X}>\dot{\mathrm{X}} \mathrm{i}+1.8 \mathrm{Sbi}$ & & & $\mathrm{X}$ & $>$ & 38 & 8 & 0.50 & $50 \%$ \\
\hline 2 & Appropriate & $\dot{\mathrm{X}} \mathrm{i}+0.6 \mathrm{Sb} \mathrm{i}<\mathrm{X} \leq \dot{\mathrm{X}} \mathrm{i}+1.8 \mathrm{Sb} \mathrm{i}$ & 36 & $<$ & $\mathrm{X}$ & $\leq$ & 38 & 2 & 0.13 & $13 \%$ \\
\hline 3 & Enough & $\dot{\mathrm{X}} \mathrm{i}-0.6 \mathrm{Sbi}<\mathrm{X} \leq \dot{\mathrm{X}} \mathrm{i}+0.6 \mathrm{Sbi}$ & 34 & $<$ & $X$ & $\leq$ & 36 & 3 & 0.19 & $19 \%$ \\
\hline 4 & Less appropriate & $\dot{\mathrm{X}} \mathrm{i}-1.8 \mathrm{Sbi}<\mathrm{X} \leq \dot{\mathrm{X}} \mathrm{i}-0.6 \mathrm{Sbi}$ & 32 & $<$ & $\mathrm{X}$ & $\leq$ & 34 & 0 & 0.00 & $0 \%$ \\
\hline 5 & $\begin{array}{l}\text { Not appropriate } \\
\mathrm{N}=\end{array}$ & $\mathrm{X} \leq \dot{\mathrm{X}} \mathrm{i}-1.8 \mathrm{Sbi}$ & & & $\mathrm{X}$ & $\leq$ & 32 & $\begin{array}{c}3 \\
16\end{array}$ & 0.19 & $19 \%$ \\
\hline
\end{tabular}


Explanation:

$\begin{array}{llr}\text { Ideal Average }(\dot{X} \mathrm{i}) & = & 1 / 2(\text { Maximum } \\ \text { Score+Minimum Score }) & & \\ \text { Raw Standard }(\text { Sbi }) & = & 1 / 6(\text { Maximum } \\ \text { Score-Minimum Score }) & \\ X & =\text { Empirical Score }\end{array}$

In addition, the data were collected by using interview about the quality of product. The results of interview can be concluded as: 1) connection of android to monitor was still not consistent, 2) manual system setting to automatic system was still not consistent. The interview results were used to improve the quality of product. The results generally were gotten by comparing questioner results with total of high score then it was found $91.4 \%$ of participants assess the product was eligible.

\section{Tool Efficiency Testing}

The data from the tool were used to test tool's consistency. Data had the unit of lamp numbers per time unit $(\mathrm{n} / \mathrm{m})$. To see the implementation of footwork, it was used coach's judgement. The result was minimum score $=1$, maximum score $=9$, mean $=4.75$, and deviation standard $=2.98$, total score that was gotten 19 in 1 minute. The following displayed data of frequency distribution of athlete footwork ability.

Data of frequency distribution showed that 52\% participant had footwork ability in interval class 1-3, $12 \%$ participant had footwork ability in interval class $4-$ 6 , and $37 \%$ participant had footwork ability in interval class 7-9. From the result can be seen tool efficiency in determining footwork ability in getting preliminary data to determine exercise intensity.

The purpose of development of this footwork tool was to develop and improve agility component, coordination and reaction speed in supporting footwork ability of badminton athletes. Participants need to run and change the direction quickly to get good position to hit and return the ball to opponent10. Reaction speed had a role in receiving the stimulus and showing in the form of anticipation movement cross the ball to the opponent area. Because of that, specific exercise that involved that component was needed in every technique and physical exercise.

The result of FGD found the form of exercise that suitable to develop footwork ability but it was still manually. The weaknesses of manual method were 1) exercise intensity was hard to be determined, 2) the accuracy the use of time was inaccurate, 3) movement pace setting was inconsistent, and 4) it was hard to do randomly. The development of footwork exercise tool consisted of two components hardware and software. Hardware consisted of panel detector device, reader detector, and panel command. Then, software device consisted of software programming.
Press panel was placed in eight sides of badminton court. Four points at the left and right court connected parallel to system control (microcontroller ATmega2560). An application program on android consisted of time data input and duration. This application was connected to panel command used HC05 module bluetooth. The advantage of this tool was to facilitate coaches and athletes to set the intensity of exercise in accordance with principle of exercise. In principle exercise must have the enhancement of intensity progressively11)12). To get the improvement regularly and measurable required footwork exercise tool that can be set systematically in improving exercise intensity.

\section{CONCLUSION}

In accordance with the results of data analysis and discussion. it can be concluded that:

Footwork exercise tool that was developed and completed with smartphone technology was accepted as exercise tool for athletes and coaches that has tested efficiently in determining exercise intensity based on maximum ability with unit of achievement numbers per time.

\section{REFERENCES}

[1] Donie. 2009. Pembinaan Bulutangkis Prestasi. Padang. Wineka Media

[2] Bompa, Tudor and Carrera, Michael. 2015. Conditioning Young Athletes. Human Kinetics: United States

[3] Bompa, Tudor and Buzzichelli, Carlo. 2015. Periodization training for sports Third Edition. Human Kinetics: United States

[4] Singh, Joseph. Raza, Suhel. Mohammad, Arif. 2011. Physical characteristics and level of performance in badminton: a relationship study. Journal of Education and Practice. Vol 2, No 5, Pages 2222-1735.

[5] Seth, Bipasa. 2016. Determination factors of badminton game performance. International Journal of Physical Education, Sports and Health. 3(1): 20-22

[6] Huang, Han-Chen. Lin, Chun-Ta. Hu, Chia-Sen. 2015. Analysis of selection indicators of badminton players by the delphi method and analytic hierarchy process. International Journal of Computer Science \& Information Technology (IJCSIT). Vol 7, No 1

[7] Yang Yang. 2014. Research of badminton forehand smash technology based on biomechanical analysis. Journal of Chemical and Pharmaceutical Research, 6(7):962-969.

[8] Yousif. B. F. Yeh, Kok Soon. 2011. Badminton training machine with impact mechanism. 
Journal of Engineering Science and Technology. Vol. 6, No. 1 Pages $61-68$

[9] Borg W. R. \& Gall M. D. (1983). Education research. (4thed). New York: Longman Inc

[10] Davis, B. et al. (2000) Training for physical fitness. In: Davis, B. et al. Physical Education and the study of sport. Spain: Harcourt Publishers, p.121-122

[11] McMorris, Terry dan Hale, Tudor. 2006. Coaching science theory into practice. Chichester: jhon wiley \& Sons, Ltd,.

[12] Dan Gordon. 2009. Coaching science. Great Britain: learning Matters Ltd. 